\title{
O MATRIMÔNIO SEGUNDO KIERKEGAARD FRENTE AO AMOR LÍQUIDO DE ZYGMUNT BAUMAN
}

Wanderley Costa de Oliveira ${ }^{1}$

\begin{abstract}
RESUMO: O conceito de matrimônio de Søren Kierkegaard (1813-1855) está expresso nos Stadier, que tem uma parte traduzida ao português como "O matrimônio". Tomamos como ponto de partida que a reflexão do autor ainda pode ser pertinente ao contexto da Modernidade contemporânea, especialmente em diálogo com o conceito de "Amor Líquido", presente na obra homônima do sociólogo polonês Zygmunt Bauman (19252017). O matrimônio, na visão de Kierkegaard, é a união de espírito em que os amantes celebram o amor, e para mantê-lo longevo, a manutenção do amor erótico é necessária, uma vez que o amor precede o matrimônio. Por outro lado, no "amor líquido", a instabilidade, a fugacidade e o consumismo impedem a realização do matrimônio, flexibilizando-o a modos instantâneos e insensíveis à afetividade. A hipótese deste artigo é a de que uma convergência entre os autores está na condição que a vida conjugal é entendida: nada é estável existencialmente que possa durar para sempre nem antes, nem depois do matrimônio. Considerando a ligação que os conceitos de Kierkegaard e de Bauman podem ter com a perspectiva existencialista na Idade Contemporânea, poderemos observar como os laços afetivos foram abalados sensivelmente no século XX.
\end{abstract}

PALAVRAS-CHAVES: Matrimônio; Amor líquido; Vida conjugal; Fragilidade das relações afetivas; Pós-Modernidade.

\section{MARRIAGE ACCORDING TO KIERKEGAARD FACING THE LIQUID LOVE OF ZYGMUNT BAUMAN}

\footnotetext{
${ }^{1}$ Licenciado em Filosofia pela Católica de Vitória Centro Universitário, e Mestre em Ciências das Religiões pela Faculdade Unida de Vitória. E-mail: davegrohl2006@hotmail.com
} 


\begin{abstract}
The concept of marriage by Søren Kierkegaard (1813-1855) is expressed in the Stadier whose part as a whole was translated as Treaty of Marriage and its reflection can still be convergent to the context of Modernity which is expressed by the concept of "Liquid Love" present in the homonymous work of the Polish sociologist Zygmunt Bauman (1925-2017). Marriage in Kierkegaard's view is the union of spirit in which lovers celebrate love so that in order to keep it long, the maintenance of erotic love is necessary while love precedes marriage. On the other hand, in liquid love, instability, fleetingness, and consumerism hinder the realization of marriage by flexing it into instantaneous and insensitive modes of affectivity. The convergence between the authors is on the condition that married life is understood: nothing is existentially stable that can last forever neither before nor after marriage. Given the connection in which the two concepts have with the existentialist perspective in the Contemporary Age from Kierkegaard and Bauman, it is possible to understand how the affective ties were shaken noticeably in the twentieth century.
\end{abstract}

KEYWORDS: Marriage; Liquid love; Married life; Weakness of affective bonds; Modernity.

\title{
INTRODUÇÃO
}

Entender a dinâmica do matrimônio em tempos modernos não é uma tarefa das mais fáceis. As dificuldades surgem desde a instabilidade das relações humanas na Modernidade contemporânea, também chamada por alguns filósofos de "pós-modernidade", até o desinteresse em debater essas questões no campo acadêmico, uma vez que este campo se apoia muito em formalismos excessivos, além de insistir em determinados assuntos até ao ponto de total exaustão de um tema. Contudo, em se tratando de Filosofia, sempre haverá relevância em discutir o matrimônio, principalmente quando temos em debate dois autores de tempos distintos, mas muito próximos em suas reflexões sobre tal questão, como é o caso do dinamarquês Søren Kierkegaard e do polonês Zygmunt Bauman. Cruzando as perspectivas dos autores surge uma questão fundamental: o "matrimônio" é possível em tempos de "amor líquido"? Para explorar essa questão, começaremos nossa análise com a reflexão de Kierkegaard sobre o matrimônio e depois nos apoiaremos nos pontos de vista de Bauman sobre o "amor líquido". 
Antes de prosseguir, tendo em vista alguns trabalhos acadêmicos produzidos acerca do matrimônio na obra de Kierkegaard, vale ressaltar que, em nosso argumento, é um equívoco tentar diluir o Tratado sobre o Matrimônio ("O Matrimônio" na versão em língua portuguesa) com os estádios ético, estético e religioso (conceitos chaves para a compreensão da filosofia kierkegaardiana), tomando o matrimônio como um estilo de vida ou um modo de vida. Este adendo procura deixar indicado, desde já, que compreender a semântica do termo "estilo de vida" não é compatível com a tendência existencialista cristã presente nos trabalhos de Kierkegaard. Esperamos que esse ponto fique mais claro ao longo da exposição.

\section{SOBRE O MATRIMÔNIO EM TEMPOS DE AMOR LÍQUIDO}

O Matrimônio ou Algumas reflexões sobre o matrimônio em resposta às objeções (por um homem casado) faz parte de uma obra maior de Kierkegaard, intitulada Etapas no caminho da vida (Stadier paa Livets Vej, no original). A obra, escrita em 1845, foi publicada sob o pseudônimo Juiz Wilhelm, e foi organizada por outro pseudônimo, o de Hilarius Bogbinder. Embora tenha sido publicada separadamente em língua portuguesa, O Matrimônio traz questões abordadas pelo autor em sua obra mais ampla, como os três estádios da existência humana (sobretudo o ético e o estético, com ênfase no religioso).

Acompanhando o argumento de Kierkegaard, vemos que o matrimônio não pode e nem deve ser entendido como um estilo ou um modo de vida. Esta constatação reside exatamente na diferença, para o autor, entre o viver e o existir. No Existencialismo, por exemplo, o existir "é situar-se em meio às coisas e ao geral humano" (OLIVEIRA, 2003, p. 21) e, no caso da vida, ocorre o processo biológico de respirar e mover-se. Em geral, a confusão vista em muitos trabalhos sobre a obra de Kierkegaard é associar aquilo que faz parte da existência com aquilo que faz parte da vida em seu plano ôntico, ou seja, das coisas e dos entes.

A existência, para o autor, é o aspecto ontológico do qual a vida é subordinada, ou seja, aquilo que o ser humano faz de sua existência, 
enquanto a tomada de consciência de si no mundo é vista como determinante para o seu modo de vida. Aqui, entende-se como modo de vida hábitos e costumes que teremos ao longo do processo em que o corpo permanece vivo biologicamente. Por isso, em Stadier, Kierkegaard não fala em estádios da vida e sim da existência. Em seus termos: "existem três esferas de existência: a estética, a ética e a religiosa.” (KIERKEGAARD, 1993, p. 693, tradução nossa), e segundo as palavras de Santos (2017, p. 99), estes estádios são como "estações de um trem":

[...] onde se pode estar em um momento em um, e outro momento em outra estação, ou até mesmo voltar à estação anterior segundo o desejo do indivíduo. O homem escolhe como seguir sua existência, escolhe diante das possibilidades que lhe são apresentadas e, nessas escolhas, vive os seus estádios, que não são vistos como degraus nos quais se vai adquirindo "maior dignidade de vivência", mas, modos do existir

Conforme já indicamos, em Kierkegaard, as esferas da existência humana gravitam entre os estádios estético, ético e religioso. $\mathrm{Na}$ obra $O$ desespero bumano, o autor manifesta sua compreensão a respeito do que é o ser humano em sua existência, ou seja, o fato de existir translada entre sua condição finita com o infinito ao qual se coloca diante de si:

O Homem é espírito. Mas o que é espírito? É o eu. Mas, nesse caso, o eu? O eu é uma relação, que não se estabelece com qualquer coisa de alheio a si, mas consigo própria. Mais e melhor do que na relação propriamente dita, ele consiste no orientar-se dessa relação para a própria interioridade. $\mathrm{O}$ eu não é a relação em si, mas sim o seu voltar-se sobre si própria, o conhecimento que ela tem de si própria depois de estabelecida. O homem é uma síntese de infinito e finito, de temporal e de eterno, de liberdade e de necessidade, é, em suma, uma síntese. Uma síntese é a relação de dois termos. Sob este ponto de vista, o eu não existe ainda" (KIERKEGAARD, 1974, p. 337). 
A existência humana, nesse aspecto, é um eu que não existe, mas que se constrói na medida em que o ser humano toma consciência de si mesmo, interiorizando-se. Essa relação de síntese é individual, ou seja, a pessoa assume sua condição enquanto um ser finito, ao mesmo tempo em que tenta se aproximar do infinito transcendendo-se de si por meio de seu espírito. Se, por um lado, o ser humano não consegue definir seu eu, quando se encontra mergulhado na temporalidade e seus derivados, por outro lado, pela transcendência de si mesmo, sente-se parte integrante desse infinito, e podemos entender que a eternidade do ser e a identificação com o Deus transcendente são tidos como objetivos existenciais para uma vida mais feliz e menos factual.

Dito isso, cabe observar que, em relação ao matrimônio, Kierkegaard o define como a união espiritual entre duas pessoas. A dimensão existencial do ser humano remete, em geral, à uma síntese entre o finito e o infinito, cuja síntese individualiza essa relação. Assim, quando duas pessoas se unem em matrimônio, tal união vai muito além do que a união de corpos reconhecida civilmente (neste caso, o casamento).

Em Obras do amor, Kierkegaard fala também do amor espiritual como sendo um amor indestrutível e permanentemente sólido, pois, à medida que o tempo passa o amor é, ao mesmo tempo, "dedicação e renúncia [...] deve julgar, se são demonstradas a dedicação e a renúncia, e se a dedicação e a renúncia demonstradas são amor” (KIERKEGAARD, 2013, p. 131). Grosso modo, essa afirmação poderia ser entendida como dedica-te ao Outro e renuncia-te a ti mesmo. Atendo-se ao tema deste artigo, o amor espiritual é a total dedicação ao Outro em "primeiro tu”, ou seja, "o Outro não se reduz a um alter ego (segundo eu, continuação imediata de meu eu imediato)" (VALLS, 2005, p. 273). O amor em "primeiro tu" é um amor desinteressado que não se apega aos atrativos corpóreos que o Outro pode trazer. Ama-se o espírito de igual modo quem ama a Deus, "pois amar a Deus, isto é que é amar verdadeiramente a si mesmo; auxiliar um outro ser humano a chegar ao amor de Deus, isto é que é amar a um outro ser humano; ser ajudado por uma outra pessoa a amar a Deus significa ser amado" (KIERKEGAARD, 2005, p. 131). 
O matrimônio, então, opõe-se ao casamento e não pode ser considerado um "modo/estilo de vida". O casamento, seguindo nessa análise, é uma instituição social marcada pela união dos bens materiais que cada um tem antes do ato de se casar, e a união de dois estilos de vida distintos que envolvem hábitos e costumes individuais contraídos ao longo da vida. Neste caso, seria mais apropriado que os termos "modo/ estilo de vida" sejam utilizados em referência ao casamento, já que ele é considerado uma união de corpos que convivem em um espaço físico (a casa) e dividem suas vidas a um modo ou estilo de vida comum ao casal.

Ainda sobre o casamento como um "modo/estilo de vida", vale apontar que o sociólogo francês Émile Durkheim entende que o casamento (e não o matrimônio por não ser objetivável e mensurável) era um fato social, por ser uma ação comum a muitos povos, variando em detalhes a respeito dos ritos. Logo, subordinar o matrimônio a um modo de vida é tentar encaixar um objeto de forma geométrica em um espaço assimétrico de suas proporções e confundir com o casamento enquanto uma instituição social, pois: "o matrimônio é a expressão típica do ético. Enquanto que na concepção estética do amor, duas pessoas excepcionais só podem ser felizes por força da excepcionalidade" (SANTOS, 2017, p. 104).

Temos, assim, que o casamento é um fato objetivo, factual. O matrimônio, por outro lado, é ao mesmo tempo um fato subjetivo e uma ação individual em se tratando de um compartilhamento mútuo em uma convivência íntima entre duas ou mais pessoas (no caso das relações poliamorosas). Sobre a convivência íntima, Kierkegaard (1994, p. 51) observa que é uma relação de:

[...] liberdade e necessidade; e mais ainda porque a liberdade aplicada à paixão é propriamente liberdade da alma. Certo que, ainda que sendo livre, a individualidade não se liberou da necessidade natural; porém, a entrega de si mesma cresce na medida em que a liberdade passa a um grau superior: somente pode dar seu eu aquele que o possui. 
No quadro histórico da Modernidade contemporânea, vemos que o panorama é distinto do descrito pelo autor. De certo modo, podemos identificar um prelúdio anunciado por Kierkegaard, e que reflete nos tempos atuais - de uma fluidez do amor -, quando o filósofo analisa as relações matrimoniais e amorosas em seu tempo em contraposição ao que ele denominou de "decadência grega":

Nossa época lembra a decadência grega: tudo subsiste, porém ninguém crê mais nas velhas formas. Desapareceram os vínculos espirituais que as legitimaram, e toda a época se nos parece tragicômica: trágica porque sombria, cômica porque ainda subsiste. Pois o perecível é sempre, em suma, o suporte do imperecível, e o espiritual do material. (KIERKEGAARD, 1994, p. 17)

Em linha semelhante à de Kierkegaard e procurando compreender o modo como se dão as relações no mundo contemporâneo, Zygmunt Bauman sugere que o "amor líquido" é um dos males da Modernidade, porque as pessoas não se sentem mais dispostas a estabelecer vínculos espirituais (como o matrimônio). Agora, para o autor, os vínculos materiais (como o casamento) são predominantes, e mesmo esses vínculos não escapam da fluidez ao qual o amor no século XX está se transformando:

[...] em uma cultura do consumo como a nossa, partidária dos produtos prontos para uso imediato, as soluções rápidas, a satisfação instantânea, os resultados que não requeiram esforços prolongados, as receitas infalíveis, os seguros contra todo risco e as garantias de devolução do dinheiro (BAUMAN, 2005, p. 22),

Seguindo a argumentação de Bauman, os tempos modernos são palcos de uma transformação que radicalizou as noções de "existência" e de "amor". Em Vida líquida, por exemplo, Bauman observa que, embora não tenha abordado diretamente a reflexão sobre a existência humana 
como fizera Kierkegaard, deixou alguns indícios de que a existência humana está ligada diretamente à vida factual, ou seja, não há diferenças entre o viver e o existir:

A vida líquida é uma vida precária, vivida em condições de incerteza constante. [...] A vida líquida é uma sucessão de reinícios, e precisamente por isso que os finais rápidos e indolores sem os quais reiniciar seria inimaginável, tendem a ser os momentos mais desafiadores e as dores de cabeça mais inquietantes (BAUMAN, 2007, p. 8).

De certo modo, Bauman analisa a condição empírica da vida líquida, indicando certas consequências causadas pela fluidez da vida, mas não aborda as questões referentes à existência humana. Este fato é constatado quando ele afirma, em linhas gerais, que "a incerteza de uma vida mortal em um universo imortal foi finalmente resolvida: agora é possível parar de se preocupar com as coisas eternas sem perder as maravilhas da eternidade" (BAUMAN, 2007, p. 15).

Digamos que, o que Kierkegaard constatou no século XIX veio a se consolidar no século XX, pois a transformação das relações amorosas entre os seres humanos foi avassaladora e derradeira para o amor romântico que suscita as paixões e o desejo de uma vida a dois. Bauman denuncia justamente a situação anunciada por Kierkegaard, mas com um agravante: cada vez mais vemos a mercantilização do amor e a capitalização das uniões afetivas, que foram transformadas em relações de negócios. Ou seja, para este autor, os indivíduos no século XX não estão mais preocupadas em buscar um amor pelo amor, mas pela garantia de estabilidade financeira que as permita consumir em abundância ou a promessa desta estabilidade para toda a vida. Nesse quadro,

há parceiros que preferem simplesmente viver juntos, sem os compromissos oficiais do casamento. Há também os Casais Semisseparados (CSS), que vivem um casamento em tempo parcial: cada um tem sua casa, sua conta bancária e 
seu círculo de amigos. Eles só ficam juntos quando sentem vontade. Bauman coloca que essas são algumas tentativas de se satisfazer, ao mesmo tempo, o impulso de liberdade e a ânsia por pertencimento (RESENDE, 2013, p. 215).

Em certa medida, estamos diante de um quadro que era o temido por Kierkegaard ainda no século XIX, no qual os indivíduos sentiam medo de se casarem não pelo ato ritualístico em si mesmo, mas pela ideia de conviver juntos sob o mesmo teto dividindo uma vida ou vidas (no caso dos filhos, quando existem). No referido século, convém lembrar que alguns se casavam sem o amor romântico. Para Kierkegaard, "os que têm o sentido do amor romântico não se ocupam do matrimônio, e muitos matrimônios são realizados, infelizmente, sem esse profundo sentimento do erótico, que é por certo o que há de mais belo na existência do homem." (KIERKEGAARD, 1994, p. 26). Neste caso, há aqui uma preocupação com a longevidade da união matrimonial quando esta se relaciona com a convivência diária entre os indivíduos, de modo que o cuidar e o amar ganham a mesma força que o desejo e a paixão como forças que mantêm a duração de um casamento.

Quando unidos por um amor espiritual ou um amor na esfera religiosa (por isso matrimônio), o Outro passa a ser amado em virtude de sua interioridade. O Outro enquanto próximo é visto como um "primeiro tu”. Nas palavras de Kierkegaard (2013, p.77), “o amor ao próximo é amor entre dois seres eternamente determinados como espírito cada um para si; amor ao próximo é amor segundo o espírito, mas dois espíritos jamais podem tornar-se um, no sentido egoístico”. No cenário da modernidade contemporânea, Zygmunt Bauman percebe que o Outro é visto como uma extensão do "eu", ou seja, a liquidez do amor é uma supremacia do egoísmo e do individualismo de modo a subordinar o Outro e relegá-lo a um segundo eu ou, em uma interpretação kierkegaardiana, um "segundo tu".

No "amor líquido", segundo Bauman, não existe intenção alguma em aprofundar as relações amorosas, somente o amor superficial e estéril fincado no solo das incertezas e das inconstâncias; trata-se, pois de uma 
relação frágil e com muitas reservas, já que existem poucas entregas afetivas entre aqueles que se amam. Na esteira das relações amorosas fluidas, amor e morte suscitam o mesmo temor nos indivíduos, ao passo de que o amor é condição para autopreservação, mas não é condição quando o mesmo amor está relacionado na preservação do Outro próximo. Em resumo, poderíamos dizer que o casamento é um contrato social firmado entre indivíduos por meio de uma certidão de casamento que oficializa a união e que, ao mesmo tempo, determina um prazo de validade, como nas bandejas de iogurtes em que ele dura enquanto ainda há copinhos de iogurtes a consumir ou que perece com o tempo se não for consumidos.

Nesse contexto contemporâneo, então, o matrimônio se torna cada vez mais raro, porque nessa liquidez do amor, casamento e matrimônio se confundem e são resumidos em uma relação de interesses, cuja dinâmica central gira em torno do dinheiro. O dinheiro é quem promove a união e, na ausência dele, muitas vezes a desunião (o divórcio). $\mathrm{Na}$ verdade, o lucro esperado nas uniões afetivas sempre está catalisado pela "segurança, proximidade, ajuda, companhia, consolo e apoio" (RESENDE, 2013, p. 215). Mas o que poderia ser o amor para Zygmunt Bauman?

O amor é o desejo de querer e preservar o objeto querido. Um impulso centrífugo, diferente do desejo centrípeto. Um impulso à expansão, a ir mais além, extender-se para o que está "lá fora". A ingerir, absorver e assimilar o sujeito no objeto, e não ao contrário como no caso do desejo. [...] no amor o eu é gradualmente transplantado ao mundo. $\mathrm{O}$ eu amante se expande entregando-se ao objeto amado. O amor é a sobrevivência do eu através da alteridade do eu. E por isso, o amor implica o impulso de proteger, de nutrir, de dar refúgio, e também de acariciar e mimar, ou de proteger ciumentamente, cercar, encarcerar. Amar significa estar a serviço, estar a disposição, esperando ordens, mas também pode significar a expropriação e admissão de toda responsabilidade. Domínio através da entrega, sacrifício que paga com engrandecimento (BAUMAN, 2005, p. 25). 
Nota-se que, na visão de Bauman, não se trata apenas de uma renúncia de si mesmo por um objetivo como se o Outro fosse condição para alcançar esse objeto. Na Modernidade, o amor romântico praticamente sucumbiu ao amor racionalizado (este que vê no Outro um meio, nunca um fim em si), algo que Kierkegaard já alertava. A existência humana é condicionada pelas incertezas e instabilidades que fazem da vida um absurdo, um labirinto cujo fim dele é a escuridão e o não-saber se chegará ao destino final dele ou não.

Desde o começo de uma relação afetiva até a morte (seja pela velhice ou pelas interrupções ao longo do tempo), o casamento está suscetível aos chamados "altos e baixos"; às crises e às incertezas que até o "sim" dado diante do altar passa até ser interpretado como um "talvez" ou simplesmente "não sei”. A Modernidade é, pois, o tempo histórico no qual o matrimônio de razão superou e praticamente exterminou o matrimônio de amor romântico. Ao racionalizar o matrimônio, o "sim" dado diante do altar se tornou um mero rito de passagem inserido em um conjunto simbólico que envolve consumo (porque faz parte de uma cerimônia de casamento com todos os custos que não são poucos), status e estética (porque a preocupação não é o ato religioso em si, mas a impressão que a cerimônia deixará nos convidados da festa).

Ao longo de Stadier, Kierkegaard discorre sobre dois tipos principais de matrimônio:

1) Matrimônio de razão (marriage de raison): é a união por interesses (por conveniência), um intermediário do amor imediato e da razão pensante, de modo que o autor identifica essa modalidade com a corrente que quer substituir o amor romântico. Ou seja, o "matrimônio raciocinado" é a união por conveniência em que não há amor e sim acordos, contrato que a qualquer momento, sem amor algum, pode ser facilmente rompido. Nessa união, a convivência entre o casal é mecânica e sem vínculo afetivo que o amor erótico proporciona. Além disso, trata-se de uma união instável - o casal se vê, muitas vezes, como dois adversários conglomerados, em que um é a causa do "mal" ao outro (o "inferno") -, e uma união estética porque está preocupada em manter aparências de um bom casamento, enquanto ele é melancólico e angustiante. Neste tipo de casamento há duas 
classes de melancolia: a "egoísta", caracterizada pela aversão ao casamento de corpos e proporcionada pela instabilidade na convivência diária em relação à falta de certezas que um tem do outro, e a melancolia "simpática à nobreza”, caracterizada pela necessidade de se afirmar na sociedade, de modo que o dinheiro, o status e a fama são preocupações maiores que a interação e a convivência.

2) Matrimonio de amor romântico: trata-se da união que é desprovida de interesses materiais e tende a ser "eterna" enquanto durar (até a morte), pois o amor e desejo são temperados pela convivência diária. Nesse matrimônio, o sensível (corpo) e o Espírito são unidos pelo amor que antecede o ato de se casar, ou seja, não há um amor em construção na convivência diária do casal, mas um amor a ser mantido, reformado e preservado porque este amor veio no decorrer do namoro e do noivado (períodos irracionais do estágio ético da existência).

$\mathrm{Na}$ visão de Kierkegaard, esse segundo matrimônio já estava ameaçado em sua época, e, como vimos a partir de Bauman, no mundo contemporâneo, ele foi quase diluído. Ou seja, na Modernidade contemporânea, o estádio estético superou o estádio ético ao invés de complementá-lo e rejeitou o estádio religioso. Enquanto o matrimônio faz parte da transição da vida em que o estádio ético dá as prerrogativas de dever ao ato de unir-se com alguém, ou seja, o casamento é um dever enquanto a instituição de uma nova família, no estádio estético habita a premissa inicial do amor líquido: relações amorosas que tem toda a aparência de durarem até o resto da vida e que, subitamente, acabam.

Recuperando o argumento de Bauman, observamos que as relações humanas se fragilizaram ainda mais com o advento da Internet e do mundo globalizado, pois os relacionamentos cada vez mais estão virtualizados e os indivíduos cada vez mais conectados com outros, estejam distantes de si, estejam muito próximos - como em apps de relacionamentos como Tinder, Happn, Badoo e etc. Trata-se de um "amor em rede" que pode durar ou não, dependendo do acionamento das funções "delete", "block" ou o encerramento da conta nesses apps. Como aponta Bauman, "diferente das 'verdadeiras relações', as 'relações virtuais' são de fácil acesso e saída. Parecem sensatas e higiênicas, fáceis de usar e amistosas com o usuário, 
quando as compara com a "coisa real", pesada, lenta, inerte e complicada" (BAUMAN, 2005, p. 13).

Nas últimas décadas do século XX e neste início de século XXI, o mundo virtual que aproximou as pessoas, também proporcionou a condição de anônimo quando essas relações eram rompidas por telefone, mensagens instantâneas (Whatsaap ou Telegram), por e-mail ou outros meios digitais. $\mathrm{O}$ contato pode ser deletado a qualquer instante sem maiores consequências. Além disso, a "oferta" é grande e é possível escolher o "produto" que seja mais agradável (RESENDE, 2013, p. 216). Muitos casamentos nascem do medo - do pânico dos indivíduos de encararem a solidão - e outros casamentos nascem da pressão social exercida àqueles que optam pela chamada "solteirice". Criam-se, então, casamentos a la carte, nos quais a interatividade e a "liberdade" de escolher o que melhor satisfazer tal necessidade traz a falsa sensação de liberdade, no qual se escolhe essa ou aquela pessoa não pela sua pessoalidade, mas por suas propriedades. De certa forma, os amantes formados nas redes virtuais mantêm-se conectados em uma espécie de Matrix, cujas consequências dessa permanência são condicionadas a uma viagem sem fim, conforme indica Bauman "[...] o itinerário é modificado em cada estação, o destino final é uma incógnita ao longo de todo o trajeto".

Em outras situações extremas, na qual a virtualidade das relações extrapola os limites da humanidade, alguns indivíduos substituem a convivência doméstica com outro ser humano por robôs ou bonecos/as sexuais hiper-realistas, feitos de resina de silicone, que são muito próximos das feições humanas ou substituem as interações humanas pelas interações com animais, como cães, gatos, hamsters, pássaros etc.

E o amor romântico? A pergunta que se faz é se todas essas modalidades de amor na "modernidade líquida" representam uma tentativa frustrada de retorno à unidade ontológica do amor, em especial ao amor romântico. Segundo Kierkegaard (1994, p. 19), "o amor romântico, com a impassividade e um endurecimento terríveis da razão, encontrou uma nova definição do amor desventurado, que consiste em ser amado, quando já não se ama, e não em amar, apesar de o próprio amor não ser correspondido." Enquanto uma nova modalidade de amor romântico, o 
amor desventurado é uma face do matrimônio de razão quando de fato não existe qualquer resquício de amor entre aqueles que estão se unindo, e se ele existe é fragilizado pelos problemas oriundos das carências consumistas, que encontram na separação a solução mais rápida.

Nas Obras do Amor, Kierkegaard fala que o amor verdadeiro nunca busca o que não lhe pertence e quando isso acontece, ele é associado ao egoísmo ou ao narcisismo que eleva a condição do eu em detrimento do Outro: “não, o amor não procura o que é seu; pois procurar o que é seu é exatamente egoísmo, amor por si mesmo, egotismo, ou qualquer outro nome que designe uma alma desamorosa" (KIERKEGAARD, 2013, p. 298). O que acontece na Modernidade contemporânea é justamente essa exaltação ao narcisismo nas relações amorosas, ao passo que as pessoas estão mais propensas a reivindicar para si e não para o conjunto social, seja a família ou a pessoa amada e seus familiares. Quando o matrimônio existe, em geral são lampejos de um amor conjugal que supera esse narcisismo moderno e, em alguns casos, são vistos até com um certo ceticismo.

Mas, o que diria Kierkegaard nos tempos de "amor líquido", no qual o matrimônio praticamente inexiste, pois, "velocidade, e não duração, é o que importa" (BAUMAN, 2007, p. 15)? Seguindo seus argumentos, podemos observar que é preciso resgatar o amor em "primeiro tu" que se perdeu no tempo, o amor espiritual indestrutível que transcende a união por casamento de corpos e que se garante perene mesmo após o fim da vida. É importante que se considere que não existe o casamento perfeito, sem crises ou sem a decadência do amor erótico. Uma vez que se concebeu o matrimônio, sua manutenção diária é mais cara e menos prazerosa do que a empreitada inicial de sedução no pleito de casar-se.

Além disso, um conselho que poderia ser dado por Kierkegaard é o de que o conhecimento profundo pelo Outro, um interesse maior pelo Outro em sua pessoalidade ou o amor pelo Outro do mesmo modo que ama a si mesmo. Pelo mandamento cristão "que vos amei uns aos outros: como eu vos amei a vós, que também vós uns aos outros vos amei” (EVANGELHO DE JOÃO, 2002, p. 142), o amor pelo Outro atende a um ordenamento espiritual; o amor cristão em sua maior plenitude, nas relações amorosas, de fato é o matrimônio e tudo que dele se origina, ou 
seja, o matrimônio de amor romântico vem confirmar a premissa inicial de que o verdadeiro amor (o amor religioso) além de ser puramente espiritual:

[...] só pode ser conhecido através de seus frutos, de suas obras, pois ele tem uma vida oculta e se revela, se manifesta na necessidade de ser reconhecido e assim se faz pelos frutos, assim como o pensamento que se revela na expressão do discurso, assim é o amor cristão que se movimenta e tem a eternidade em si (SILVA, 2012, p. 36).

Por outro lado, para aqueles que concebem o matrimônio de razão, Kierkegaard deixa o alerta de que não adianta insistir em uma relação formada pelos interesses materiais, porque além de estarem distantes do amor divino, a tendência é a de que tenha pouquíssima duração ou sequer ocorra:

Do que se deduz, também, que os matrimônios contratados por um determinado tempo não oferecem vantagem alguma, posto que comportam as mesmas dificuldades dos contratados por toda a vida; e é tão possível que brindem aos interessados a força necessária para viver, como que desgastem, por outro lado, as energias profundas da união conjugal, relaxem a tensão da vontade e diminuam a confiança, essa bênção do matrimônio. Além do mais, já está claro, e o veremos ainda melhor mais adiante, que esta classe de associações não alcançou a consciência de eternidade que caracteriza a moralidade, e que é necessária para a união em um matrimônio. (KIERKEGAARD, 1994, p. 22)

O matrimônio pode mesmo existir em tempos de "amor líquido"? Sim, o matrimônio saudável pode ser consolidado entre as pessoas se elas não se enxergarem como mercadorias a serem desejadas para o consumo e o descarte quando não mais servirem aos desejos próprios, ou se as pessoas não se deixarem levar pelo status que o consumismo traz em forma de ostentação de posses proporcionado pela falsa sensação de bem 
estar, que em pouco tempo é desfeita em virtude desse casamento ter sido edificado em solos alagadiços. A "receita" dada por Kierkegaard é amar aquela pessoa naquele dia e no outro dia amar da mesma forma já sabendo que naquele outro dia, a pessoa não estará disposta como no dia anterior, ou seja, cada um deve ser como de fato é sem que um exija mais do que o outro pode proporcionar:

"Não peço tanto, me conformo com menos: longe de mim a ideia de exigir que me ames por toda a eternidade; basta que me ames no momento em que desejo." Esses amantes sabem muito bem que o sensível perece; porém sabem, também, que é o momento mais belo, e isso lhes basta. Desde logo, uma tal corrente revela uma imoralidade absoluta; porém, em troca, segundo essa ideia, constitui, em certo sentido, um progresso para nosso objetivo, na medida em que apresenta uma denúncia contra o matrimônio. Porém, quando essa concepção trata de cobrir sua sensualidade como uma vestimenta mais decente, então se limita a um instante isolado, e sim o faz durar no tempo, de tal modo, sem dúvida, que tome consciência não do eterno mas do temporal, se bem que se aferre a essa oposição do eterno, representando-se por uma mudança sensível no tempo. (KIERKEGAARD, 1994, p. 19-20)

Kierkegaard sugere, dessa forma, que independente das circunstâncias que levaram a pessoa ao matrimônio (medo de morrer sozinho, desamparo, desejo de ter filhos/as etc.), a eternidade do matrimônio ou a consumação da frase "até que a morte os separe" só terá efeito se os amantes não forem tomados pelo medo de algo que antecedeu o matrimônio. Em outras palavras, apenas o amor espiritual, o amor verdadeiramente religioso (no sentido de religar, unir dois espíritos) triunfará sobre o amor líquido superando assim o estado de medo e incerteza nos relacionamentos. Convém notar, em particular, que quando falamos do medo de si, o "medo" é o nome que damos a nossa incerteza: nossa ignorância da ameaça e do que deve ser feito - do que pode e do que 
não pode - para fazê-la parar ou enfrentá-la, se cessá-la estiver além do nosso alcance" (BAUMAN, 2008, p. 8). Diante disso, a saída será o salto no escuro ou o salto da fé que o estádio religioso kierkegaardiano sugere.

Isso não quer dizer que do salto no escuro surgira um vale tudo para manter o matrimônio ou para rompê-lo, mas que esteja consciente daquilo que Bauman (2008, p. 08) lembra: "na escuridão, tudo pode acontecer, mas não há como dizer o que virá. A escuridão não constitui a causa do perigo, mas é o habitat natural da incerteza", que se houver qualquer senso de certeza, mesmo sendo o desejado, o matrimônio também estará fadado ao fracasso.

\section{CONSIDERAÇÕES FINAIS}

Ao longo de todo o artigo, procurou-se expor em linhas gerais a visão kierkegaardiana a respeito do matrimônio e buscou-se estabelecer certas conexões com o conceito pós-moderno de fragilidade dos laços afetivos humanos da obra Amor líquido, de Zygmunt Bauman. Em tempos de incerteza, no qual os indivíduos estão à procura de si mesmas, tanto o casamento quanto o matrimônio podem ser soluções viáveis para o alívio dessa busca sem um dado fim.

Em um mundo no qual a virtualidade é responsável também pelo desejo de se unir a alguém que esteticamente melhor agrade, Bauman nos fala que a procura por uma união ideal perpassa a ideia que introjetamos o nosso tipo ideal de pessoa à uma estética instável e inconsistente, de modo que "quando confrontados com uma imagem fotograficamente/ eletronicamente obtida, nada parece erguer-se entre nós e a realidade; nada que possa capturar ou distrair nosso olhar" (BAUMAN, 2008, p. 30)

Nossa hipótese é a de que essa estética instável é a sensibilidade da qual fora alertada por Kierkegaard, e que a Modernidade contemporânea soube absorver muito bem: as relações afetivas são como um caminhar em um solo composto de vitórias-régias que aparentemente são sólidas, mas o fato de estarem edificadas na água expõe o risco de não saber qual a profundidade e se será possível voltar à superfície após a submersão. 
Viver o amor e permanecer nele é tão difícil quanto encontrar o próprio amor, porque, para encontrá-lo, é preciso permanecer em amor (acessível para ele) para ser reconhecido por ele: "só aquele que permanece no amor pode conhecer o amor do mesmo modo como seu amor deve ser conhecido" (KIERKEGAARD, 2013, p. 20). Por outro lado, na liquidez moderna do amor, o que se ama não é a pessoa por inteiro, nem pelas metades, mas pelo que ela representa enquanto uma ideia agradável que faz os indivíduos se atraírem por alguns instantes e por outros se retraírem após suas satisfações realizadas, são os relacionamentos à distância. Uma pergunta que surge nessa discussão: será que quem amo goza de tamanha perfeição do qual idealizo ou será que tenho fantasia a partir daquilo que ela mostra ser por fotografias? Nos termos de Bauman:

Minha amada poderia ser uma tela do qual pinto minha perfeição em toda sua magnificência e esplendor, mas não aparecerão também manchas e borrões? Para limpá-los, ou para ocultá-los em caso de estarem muito aderentes e seja impossível eliminá-los, tem de limpar e preparar a tela antes de começar a pintar, e logo estar muito atento para me assegurar de que os rastros da antiga imperfeição não emergirão de seu esconderijo em sucessivas capas de pintura. Cada momento de descanso tem um preço, tem que restaurar e repintar sem descanso (BAUMAN, 2005, p. 35).

Nesse horizonte não há qualquer certeza de que o amor superará o deserto que se transformou o mundo real na fluidez das coisas e na instabilidade emocional, que faz os indivíduos recorrerem ao fugaz e o supérfluo enquanto alívio imediato à angústia que se tem quando surge a questão se é possível amar e ser amado por alguém. Ainda que haja um eclipse do amor romântico na Modernidade contemporânea, ele ainda subsiste e respira com ajuda de aparelhos, e, embora não se saiba se o amor permanece ou não, "talvez mais exatamente, a questão de saber se agora, de fato, em tal ou qual caso particular ele permanece ou cessa, é algo que das mais variadas maneiras ocupa os pensamentos dos homens" (KIERKEGAARD, 2013, p. 341). 


\section{REFERÊNCIAS BIBLIOGRÁFICAS}

BAUMAN, Zygmunt. Amor líquido: acerca de la fragilidad de los vínculos humanos. Buenos Aires: Fondo de Cultura Económica, 2005.

BAUMAN, Zygmunt. Medo líquido. Rio de Janeiro: Editora Jorge Zahar, 2008.

BAUMAN, Zygmunt. Vida líquida. Rio de Janeiro: Editora Jorge Zahar, 2007.

EVANGELHO DE JOÃO. Português. In: Bíblia sagrada. São Paulo: Sociedade Bíblica do Brasil, 2002.

KIERKEGAARD, Søren. Stadi sul cammino della vita. Milano: Rizzoli, 1993.

KIERKEGAARD, Søren. O desespero bumano: Doença até a morte (1849). Coleção “Os pensadores”. São Paulo: Abril Cultural, 1974.

KIERKEGAARD, Søren. O matrimônio. Campinas: Editora Psy, 1994.

KIERKEGAARD, Søren. As obras do amor: algumas considerações cristãs em formas de discursos. Petrópolis: Vozes, 2013.

\section{PÁGINAS DA WEB CONSULTADAS}

OLIVEIRA, André Luiz Holanda. A noção de existência autêntica em Kierkegaard. Dissertação de Mestrado apresentada ao Programa de Pós-Graduação em Filosofia da Universidade Federal de Pernambuco, 2003. Disponível em: https://repositorio.ufpe.br/ bitstream/123456789/6493/1/arquivo9009_1.pdf. Acesso em: 19/05/2019.

RESENDE, Adriana Torquato. "Amor líquido: sobre a fragilidade dos laços humanos - resenha". Revista Trama Interdisciplinar, São Paulo, v. 4, n. 2, pp. 214-218, 2013. Disponível em: http://editorarevistas. mackenzie.br/index.php/tint/article/view/6414/4543. Acesso em: 21/05/2019. 
SANTOS, Rômulo Gomes dos. "Reflexão sobre os estádios existenciais em Søren Kierkegaard”. Revista Guairacá de Filosofia, Guarapuava, v. 33, n.1, pp. 95-116, 2017. Disponível em: https://revistas.unicentro. br/index.php/guaiaraca/article/download/5065/3469. Acesso em: 19/05/2019.

SILVA, Jadson Teles. "Acerca das noções de amizade e amor: contrastes entre Aristóteles e Kierkegaard”. Revista Kinesis, Marília, v.4, n. 8, pp. 27-39, 2012. Disponível em: https://www.marilia.unesp.br/ Home/RevistasEletronicas/Kinesis/jadsonsilva_3.pdf. Acesso em: 13/09/2019.

VALLS, Álvaro Luiz Montenegro. "O elogio do amor desinteressado em As Obras do Amor". Revista Filosofia Unisinos, v. 6, n.3, pp. 267-275, 2005. Disponível em: http://www.revistas.unisinos.br/index.php/ filosofia/article/view/6365. Acesso em: 12/09/2019.

Texto recebido em 23/05/2019 e aprovado em 08/09/2019 